\title{
MARKETING \& AGRIBUSINESS UM ENFOQUE ESTRATÉGICO
}

\section{$\star$ Mário Otávio Batalha}

dmob@power.ufscar.br

is Andrea Lago da Silva

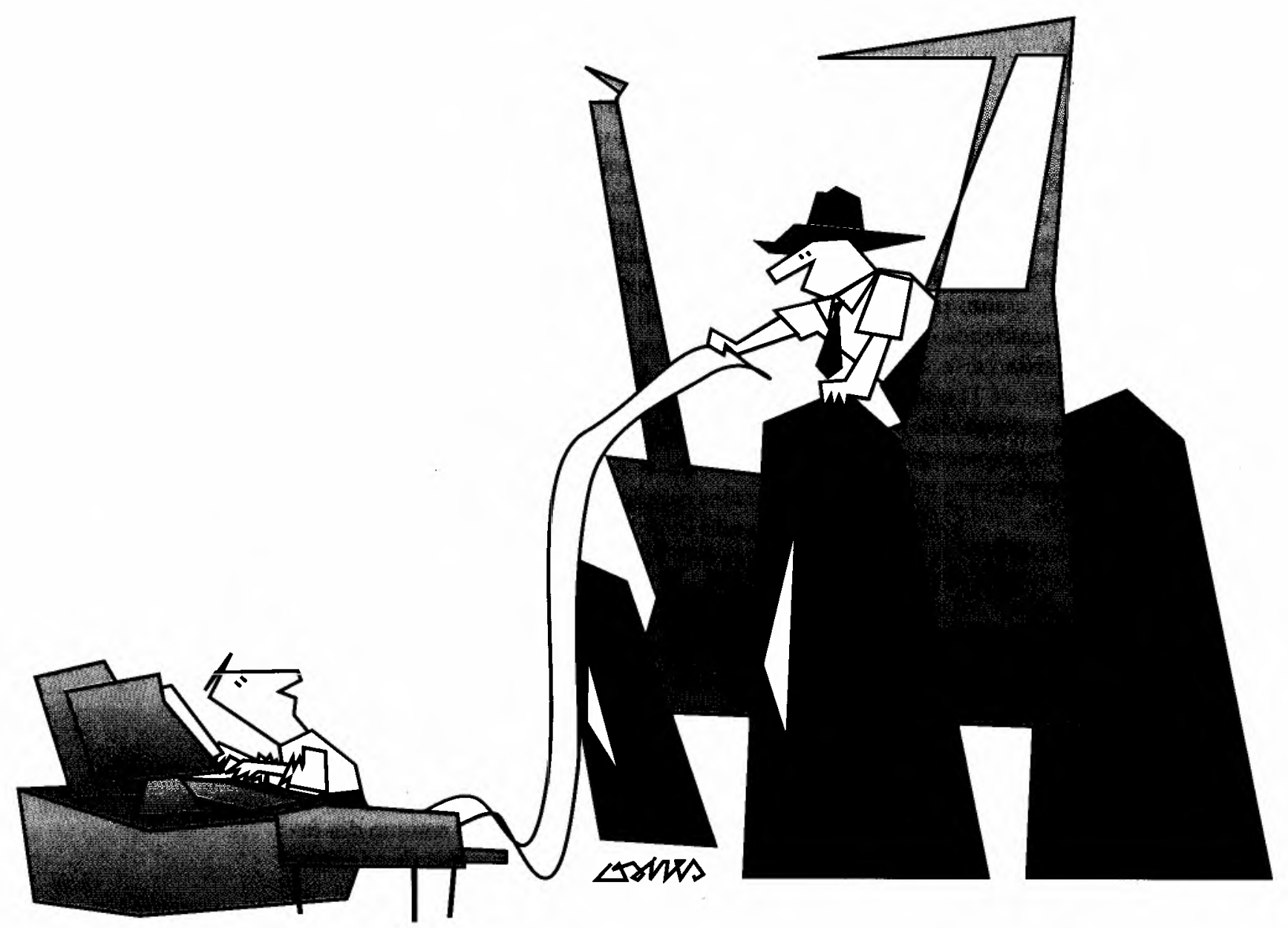

\section{PALAVRAS-CHAVE:}

mercado, agribusiness, Marketing, sistema agroindustrial, cadeia agroindustrial, complexo agroindustrial.

\section{KEY WORDS:}

market, agribusiness, Marketing, Agri-Food System, commodoties system, Agri-Food complex.

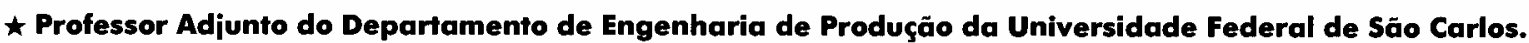
it Professora Assistente do Departamento de Engenharia de Produção da Universidade Federal de São Carlos. (rae@eaesp.fgvsp.br) Assinatura Email 


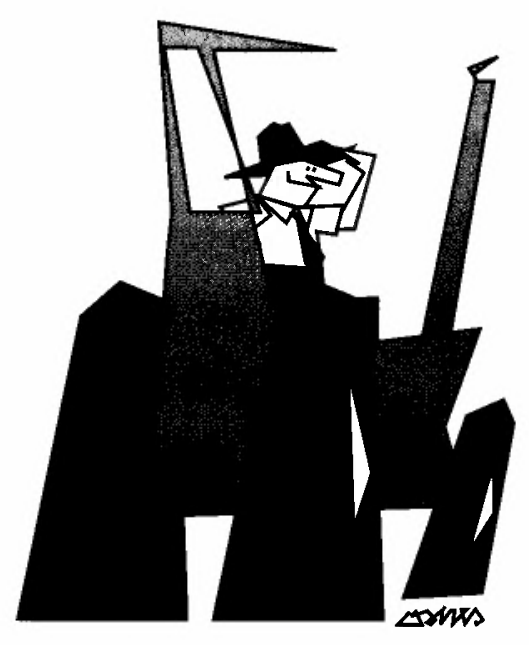

O procedimento de identificar e caracterizar os vários mercados que compõem uma cadeia agroindustrial, visando a descrever as condições de aplicação dos conceitos e técnicas de marketing a tais mercados, tem sido pouco discutido na bibliografia sobre o assunto. Este artigo pretende demonstrar que não existe sentido falar de um Marketing Agroindustrial. Assume-se aqui que o tipo de enfoque a ser adotado, as ferramentas a serem utilizadas e as variáveis a serem consideradas mudam segundo a sua posição dentro da cadeia agroindustrial e do mercado para o qual as estratégias de marketing se destinam.

O Sistema Agroindustrial (SAI) pode ser abordado segundo quatro níveis de análise. O primeiro, menos indicado para o estudo aqui proposto, é o próprio SAI. O segundo, também não contemplado neste trabalho, é formado pelos vários complexos agroindustriais que formam o SAI (complexo soja, complexo leite, complexo sucro-alcooleiro etc). A formação de um complexo agroindustrial exige a participação de um conjunto de cadeias produtivas, cada uma delas associada a um produto ou a uma família de produtos. Este é o terceiro nível de análise. Por fim, o quarto nível de análise é representado pelas várias Unidades Socioeconômicas de Produção (USEP) que participam em cada cadeia. É no exame da dinâmica de funcionamento desses dois últimos níveis que o analista de Marketing deve centrar suas atenções.
Por isto, é nestes dois últimos níveis que este artigo se posiciona.

\section{O SISTEMA AGROINDUSTRIAL (SAI) E OS SEUS MECANISMOS DE ARTICULAÇÃO INTERNA}

Uma cadeia de produção, esteja ela caracterizada como agroindustrial ou não, articula-se por meio de mercados. Um dos procedimentos fundamentais na definição desses mercados é a identificação do tipo de necessidade que os produtos presentes no mercado procuram satisfazer junto a um dado grupo de consumidores. Para atender a suas necessidades, os consumidores podem, eventualmente, recorrer a produtos oriundos de cadeias de produção agroindustrial diversas. A manteiga e a margarina, respectivamente produtos ligados ao leite e aos óleos vegetais (principalmente soja), apesar de advirem de cadeias de produção agroindustriais diferentes, com características técnicas e estruturais também diferentes, podem, neste caso, ser considerados como concorrendo em um mesmo mercado (produtos substitutos). Assim, cadeias diferentes podem contribuir para a fabricação de produtos concorrentes em um mercado específico ${ }^{1}$. Esses produtos se originam de operações técnicas internas divergentes. Em outras palavras, uma operação técnica de uma cadeia do sistema pode dar origem (ou participar de) a um mercado externo ao espaço de análise delimitado inicialmente. Os mercados exter-
1. BATALHA, M.0. La filière comme outil d'analyse stratégique: le cas des matières grasses à tartiner au Brésil. Institut National Polytechnique de Lorraine/ Institut de estion Internationale Agro-alimentaire, Paris, França, 1993 (tese de doutorado). 
nos não devem ser negligenciados na análise. Isto fica patente quando se observa que tais mercados participam como elementos ponderáveis na alocação de recursos das empresas e, ainda, que na maioria das agro- te, que deve ser entendido pelo homem de Marketing. Não basta decompor a cadeia segundo as empresas que dela participam. É preciso decompô-la nas várias operações técnicas elementares pelas quais os produ-

\section{Não se pode definir instrumentos de Marketing que sejam homogêneos e aplicáveis em todos os mercados que participam da dinâmica de funcionamento do SAI.}

\section{Idem, ibidem.}

3. FLORIOT, Jeann-Louis, Génie des systèmes industriels et management de la technologie Nancy, França: Institut National Polytechnique de Lorraine-IMPL, 1986 (tese de doutorado). indústrias a participação nesses mercados deve-se a critérios técnicos incontornáveis. No entanto, as consideraçōes do artigo privilegiarāo os mercados internos às cadeias, pressupondo-se que os mercados externos assumirão características semelhantes às que serão aqui expostas, contornando, desta forma, o problema da maior ou menor linearidade das cadeias.

Neste ponto da discussão, pode-se diferenciar dois tipos de mercados: os internos e os externos às cadeias originalmente definidas como pertinentes ao campo analítico em questão ${ }^{2}$. Considerando o citado exemplo do mercado definido pela manteiga e pela margarina, o leite fluido, a sobremesa lactéa, o queijo etc. poderiam ser vistos como de mercados externos ao espaço analítico principal: que foi definido como sendo o conjunto das cadeias de produção da manteiga e da margarina.

Uma determinada cadeia de produção agroindustrial caracteriza-se pela seqüência de operaçōes técnicas necessárias para a passagem de um produto em determinado grau de acabamento - em relação ao produto final - a um outro, mais avançado. Esse conjunto de operaçóes técnicas elementares (O.T.E.), e a forma como elas se articulam definem a arquitetura do sistema ${ }^{3}$. Os mercados nascem do fato de as empresas nāo poderem ou, em alguns casos, não julgarem conveniente realizar todas as opcraçōes. Assim, elas realizam uma parte do processo e vendem a matéria-prima parcialmente elaborada a uma outra empresa, que avançará no processo de produção. Cada uma dessas operaçōes está sutjeita a um "ambiente tecnológico" diferen- tos passarn. A análise dessas operações permitirá detectar novas oportunidades de mercado para a empresa. As operaçóes técnicas são também fontes potenciais de sinergias importantes, que não devem ser negligenciadas.

A primeira idéia que perpassa o estudante de Agribusiness (entendido, neste artigo, como sendo o conjunto de relaçóes técnicas, comerciais e de capital que se estabelecem entre os atores do SAI), é aquela de interdependência sistêmica entre os atores que compõem o conjunto e os efeitos de açāo e reaçāo que se desenvolvem entre os vários elos das suas cadeias formadoras. Esta visão sistêmica também deve ser utilizada pelo estudioso em Estratégia e Marketing aplicado ao SAI. Os vários elos formadores da cadeia estão intimamente ligados por relaçōes comerciais, tecnológicas e de capital, de forma que o analista não deve, em hipótese alguma, sob pena de incorrer em erros de avaliaçẫo fatais para a empresa, descuidar do consumidor final do produto (seja ele um consumidor individual ou uma instituição pública ou privada).

Mesmo os homens de marketing que atuam nos elos iniciais da cadeia produtiva (comércio de insumos agrícolas, por exemplo) não devem esquecer que o seu produto, visto do ângulo do conjunto das operaçōes de transformação, é somente uma matéria-prima (ou insumo de produção) que tem como objetivo atender a uma demanda final, representada por produtos específicos posicionados no fim da cadeia. É a combinaçāo dessas demandas finais (internas ou externas ao complexo delimitado inicialmente) que, em última análise, 
determinará a dinâmica do seu mercado. Esta visão integrada de demanda derivada deve ser adotada em todos os mercados que compõem as cadeias produtivas do SAI.

Assim, as metodologias de análise e as recomendações estratégicas, bem como as condições nas quais o marketing é exercido, variam segundo o posicionamento do mercado analisado dentro da cadeia.

Uma cadeia de produção agroindustrial pode ser representada como mostrado na figura 1, que explicita os três macrossegmentos que compõem uma cadeia agroindustrial genérica: macrossegmento produção de matéria prima, industrialização e comercialização. Cada um deles é delimitado por mercados com características de funcionamento diferentes, podendo se resumir apenas a mercados potenciais se, por exemplo, o complexo em questão for completamente integrado verticalmente. Seguindo as características próprias à dinâmica de funcionamento de cada um desses mercados, foram identificados e caracterizados quatro tipos de mercado, junto aos quais as atividades de marketing devem sofrer adaptação: Marketing Rural, Marketing Agrícola, Marketing Agroindustrial e Marketing Alimentar.

Esta divisão é útil para posicionar o profissional de marketing dentro da cadeia de produção agroindustrial e indicar-lhe seu foco de atenção (quais atividades estão a montante e a jusante de suas próprias atividades). Face à diversidade de tipos de organização que atuam em praticamente todos os segmentos da cadeia ${ }^{4}$ e dos tipos de contrato que esta pratica, fica difícil definir de maneira absoluta as especificidades de cada um desses enfoques de marketing. No que tange a este trabalho, a literatura diferencia, basicamente, o "marketing industrial" e o "marketing de produtos de consumo final" (produtos não-intermediários). Em cada um desses conjuntos de conhecimentos buscaram-se as idéias apresentadas a seguir. Na parte seguinte do trabalho, a figura 1 será percorrida de jusante a montante; cada uma das etapas e cada um dos vários mercados ali apresentados serão comentados. Os insumos, por justificativas que escapam ao escopo deste trabalho, não foram considerados como fazendo parte da cadeia.

\section{MARKETING AO LONGO DA CADEIA AGROINDUSTRIAL}

O estudo de Marketing reveste-se de aspectos característicos segundo os vários mercados que compóem as cadeias agroindustriais. Esta parte do trabalho é dedicada a explorar algumas destas características.

\section{Marketing Alimentar}

O Marketing Alimentar situa-se no nível do consumidor final. É representado, principalmente, pela venda do comércio varejista ao consumidor final. Caracteriza-se por um grande número de consumidores e um número restrito de distribuidores.

O estudo do Marketing Alimentar possui duas vertentes igualmente importantes: o marketing do produto propriamente dito e o marketing associado aos canais de distribuição (Marketing da Distribuição).

\section{Marketing do Produto}

A principal arma utilizada pelas empresas, neste ponto da cadeia, é a diferenciação do produto ${ }^{5}$. As empresas buscam distinguir o produto para escapar da concorrência via preços e se apropriar de ganhos monopolísticos. Ou seja, as empresas procuram destacar seus produtos aos olhos do consumidor final.

A possibilidade de diferenciação está ligada à capacidade tecnológica da empresa, ao capital disponível para investir em desenvolvimento da marca e nos atributos multidimensionais do produto. Usa-se, nesta etapa, as segmentações clássicas de "produto-mercado" ou outros critérios de segmentação como, por exemplo, o de "estilos de vida". A matriz de "segmentação combinada" proposta por Porter ${ }^{6}$ pode ser um instrumento privilegiado nesta etapa da análise. Nas linhas da matriz podem ser colocadas as características do produto (tamanho, peso, sabor, preço, embalagem etc.) e, nas colunas, as características do consumidor (idade, nível de renda, região geográfica, religião, estilo de vida etc.). Na intersecção de cada linha com cada coluna existe um segmento de mercado potencial que deve ser analisado. É evidente que quanto maiores forem os atributos do produto (no senso "lancasteriano" do termo) maiores serão as possibilidades de diferenciação.
4. MALASSIS, L. Economie Agro-alimentaire. Paris: Cujas, 1979.

5. CONNOR, J.M. et al. The food manufacturing industries. Lexington: Lexington Books, 1985; Food processing. Lexington: Lexington Books, 1988.

6. PORTER, M. L'avantage concurrentiel. Paris: Inter Editions, 1992. 


\section{Figura 1 Os diferentes enfoques: do Marketing no interior de um complexo agroindustrial}

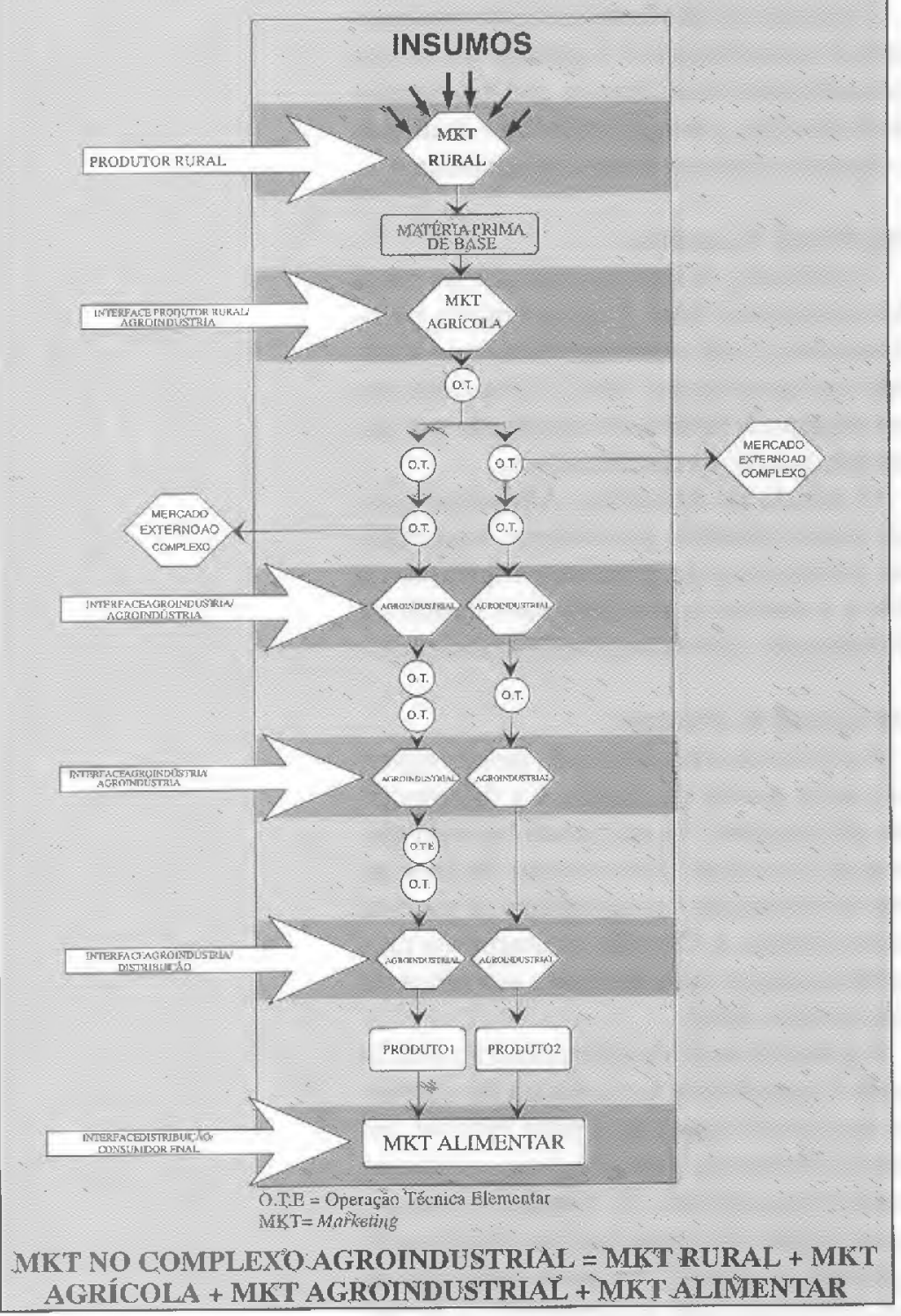

7. BLANC. G., DUSSANGE, P., QUELIN, B. Stratégies concurrentielles et différenciation., Annales de mines, p. 18-25, Paris, set. 1991.

8. BATALHA, M. O., ESCLASSE, $M$. Les corps gras solides au Brésil: étude de la qualité perçue. Revue Economie \& Gestion Agroalimentaire, Paris, n. 27, p. 10-15, abr. 1993.

9. PANIGYRAKIS, G. La qualité perçue des produits agroalimentaires. mimeo IGIA, Cergy-Pontoise, 1991.

10. Idem, ibidem.
Alguns produtos alimentares são, por natureza, de díficil diferenciação do ponto de vista técnico (intrínseco) como, por exemplo, água mineral, carne, frutas etc. Neste caso, a empresa pode recorrer ao que alguns autores chamam de "pseudodiferenciação"7. Esta "pseudodiferenciaçāo" pode ser efetuada principalmente por meio de esforços de desenvolvimento da marca do produto e/ou família. Trata-se de implantar na mente do consumidor uma "imagem-qualidade" do produto que o diferencie dos demais. Assim, a qualidade percebida pelo consumidor pode diferenciar o produto de um outro, concorrente. ${ }^{8}$ A "qualidade percebida" de um alimento pode ser definida como sendo "o conjunto de conhecimentos, crenças e impressões que o consumidor tem do produto" ${ }^{\prime \prime}$.

Segundo Panigirakis ${ }^{10}$, a qualidade de um produto alimentar pode ser percebida pelo consumidor segundo estes cinco conjuntos de critérios, de ordem subjetiva ou objetiva:

- facilidade de acesso: critério associado à disponibilidade do produto no mercado;

- características nutritivas: atributos como quantidade de proteínas, de lipídios, de de glicídios, de sais minerais, de vitaminas etc. Esses atributos estão associados a estas características e podem ser mensurados objetivamente (tecnicamente);

- características organolépticas: cor, sabor, odor, textura etc. Para o consumidor é necessário que um produto dieteticamente saudável venha acompanhado de propriedades organolépticas agradáveis; - características socioeconômicas: características associadas principalmente a ocasiōes onde um alimento é consumido (um alimento consumido em uma ocasião festiva não tem a mesma carga de "qualidade percebida" que um consumido no dia-a-dia) e à identificação de dado alimento com determinada posição social (o caviar e o champanhe para as classes mais ricas, por exemplo);

- características de utilização: facilidade na manipulaçăo de um alimento e o tempo de preparo. Essas características também tendem a alterar a qualidade percebida dos alimentos.

É evidente que cada um destes conjuntos de critérios, isoladamente ou em grupo, pode ser enfatizado para distinguir determinado produto.

Para alguns produtos de díficil diferenciação resta a opção de concorrer via preços. Neste caso, obter economias de escala e proceder a um controle estrito dos custos de produçāo devem representar o principal eixo estratégico da empresa.

Para resumir, pode-se dizer que o Marketing Alimentar não difere substancial- 
mente daquele aplicado em outras mercadorias de consumo de massa vendidos pela grande distribuição. Entretanto, cabe relembrar algumas das estratégias mais adotadas pelas firmas agroindustriais: diferenciação, diversificação, proliferação de marcas e "pseudodiferenciação". Os exemplos de concorrência via custos também são abundantes, mas, por força mesmo da "filosofia de Marketing", as empresas buscam cada vez mais diferenciar estes produtos.

Finalmente, é preciso ressaltar a importância do Modelo de Consumo Alimentar $(\mathrm{MCA})^{11}$ desempenha no Marketing Alimentar. O MCA pode ser definido como a forma pela qual os grupos de determinada população organizam-se para o seu consumo alimentar.

\section{Marketing da Distribuição}

O Marketing da Distribuição está associado ao posicionamento do estabelecimento de vendas frente às necessidades do consumidor. Segundo a orientação do contexto no qual se desenrola o processo de compra, o consumidor pode escolher determinado estabelecimento (ou outra fórmula de distribuição) pela sua avaliação da imagem dos pontos de venda, em relação ao critério que condiciona a escolha ${ }^{12}$. Desta forma, pode-se falar em posicionamento e diferenciaçāo no nível dos estabelecimentos de distribuição.

Assim, existem dois conjuntos de fatores que influenciam o processo de escolha do consumidor quanto aos produtos alimentares. Um deles é ligado às características do produto, conforme visto no item anterior. O outro, objeto deste item, é ligado às facilidades oferecidas pelo ponto de venda (proximidade do domicílio, rapidez de passagem nos caixas, estacionamento, limpeza etc.). Estas exigências dizem respeito ao ponto de venda propriamente dito e não aos produtos oferecidos, mesmo se considerando que as duas dimensões estão, evidentemente, em interaçāo ${ }^{13}$.

É evidente que esses fatores não têm o mesmo peso, variando segundo o tipo de produto comprado, como, por exemplo, $o$ processo de compra de um litro de leite e o de um automóvel. Mas, mesmo dentro do item alimentação a situação também pode variar bastante: a compra cotidiana de pão e a de champanhe para uma ocasião festiva revelam um outro exemplo. Filser ${ }^{14}$ enumera cinco cenários de compra para os produtos alimentares:

- compras agrupadas: produtos alimentares não-perecíveis, podendo ser estocados (arroz, feijão, açúcar etc.);

- compras para uma ocasião festiva: churrasco, feijoadas, Natal, Páscoa etc.;

- compras na saída do trabalho: pão, leite etc.;

- compras correntes: carne, verduras etc.;

- compras imprevistas: sal, óleo vegetal, ovos etc.

O profissional de marketing deve ser capaz de posicionar o seu produto em uma (ou várias) dessas categorias. Esse posicionamento permite identificar os canais de distribuiçāo mais adequados aos produtos e, assim, conquistar mercado e espaço junto ao distribuidor.

Enquanto alguns produtos alimentares são dominados pela marca dos fabricantes, outros o são pelo marketing dos estabelecimentos que os vendem, como, por exemplo, frutas, verduras, carne e produtos de marca branca ou própria, que têm ganhado espaço no mercado brasileiro em tempos recentes. Neste caso, o consumidor deve confiar na garantia que o supermercado aporta ao produto que está vendendo. Com as crescentes exigências acerca da origem dos produtos e informaçōes necessárias nas embalagens, os distribuidores têm passado a incluïr informações sobre quem são seus fornecedores, como forma de garantir o produto vendido.

Existe uma tendência mundial de segmentação, cada vez mais fina, das fórmulas de distribuição alimentar. $\mathrm{O}$ aumento da concorrência e a diminuição das margens a que esta concorrência induz tornaria cada vez mais rentável estratégias de nichos. No âmbito do mercado internacional, as redes de discount stores já são uma realidade. No Brasil, as fórmulas de distribuição já estão começando a sofrer as conseqüências dessas mesmas tendências. A concentração crescente da distribuição alimentar nas mãos dos hiper e supermerca-
11. PADILLA, M. Le concept de modèle de consommation alimentaire et la théorie de la consommation. In: Economie agrolimentaire: concepts et méthodes. Paris: Cahiers de I'ISMEA, p. 15-35, 1992.

12. FILSER, M. La dynamique des canaux et formules de distribution: une approche méthodologique. Montpellier, França: Universidade de Montpellier I, 1985 (tese de doutorado).

13. DUCROCQ, C. Concurrence et stratégies dans la distribution. Paris: Vuibert Entreprise, 1991.

14. FILSER, M. Op. Cit. 
dos, bem como o sucesso que vem alcançando, em grandes centros, algumas redes de lojas de conveniência, são exemplos que atestam as mudanças no sistema de distribuição alimentar no Brasil.

A evolução dos modelos de distribuição de alimentos e o poder de barganha cada vez maior dos distribuidores têm influência direta sobre o conjunto das cadeias de produção agroindustriais. $\mathrm{O}$ profissional de marketing, esteja ele envolvido diretamente ou não com a distribuição, deve estar atento a essas mudanças quando da elaboração de estratégias empre-

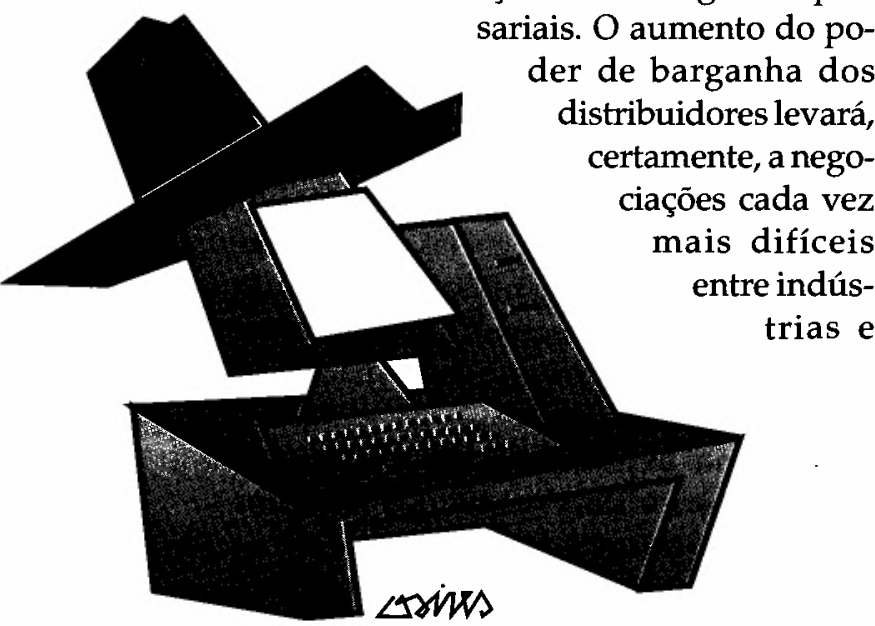

distribuição. Os fabricantes devem estar prontos para oferecer não só promoções em termos de preços e prazos mas também produtos "exclusivos", o que demanda uma maior flexibilidade nas linhas de produção. Por outro lado, não se deve esquecer que o surgimento de um novo canal de distribuição pode significar novas oportunidades de apresentação e escoamento para um dado produto. Finalmente, convém lembrar que as modificações na agroindústria podem afetar diretamente a agropecuária, o que acarreta, como havia sido mencionado anteriormente, modificações ao longo de toda a cadeia.

\section{Marketing Agroindustrial}

Os mercados situados entre o macrossegmento "industrialização" e "distribuição", bem como entre os vários segmentos de produção que caracterizam o macrossegmento industrial, formam o Marketing Industrial. Apresentam-se, a seguir, algumas características do Marketing Indus- trial ${ }^{15}$ e a forma como elas se adaptam aos mercados agroindustriais.

* Número limitado de compradores e/ou vendedores. Esta é uma característica da maioria dos mercados em questão. As firmas de produção agroindustriais caracterizam-se por uma estrutura oligopolizada, quer seja ela diferenciada ou competitiva, e por distribuidores com um grau de concentração cada vez maior. É verdade que muitas vezes os grandes supermercados tentam ativar as pequenas e médias empresas (franjas dos oligopólios) como forma de fazer concorrência aos grandes grupos. Entretanto, para alguns produtos de referência esta substituição é praticamente impossível. Convém relembrar a importância que as já citadas "marcas dos distribuidores", também conhecidas como "marcas brancas", assumiram na Europa e nos EUA., e o potencial que elas representam para $o$ Brasil.

* Compradores e vendedores bem informados (decisão coletiva de compra). Não existem dúvidas de que o serviço de compra e venda entre agroindústria/ agroindústria e agroindústria / distribuição deixou, há muito tempo, de ser amadorística. Essa função é representada, na maioria dos casos, por bem montados departamentos funcionais no interior das firmas. No caso dos supermercados, uma boa compra é fundamental para o lucro do negócio. Os compradores negociam ferrenhamente prazos, promoções, padrões de qualidade, prazos de entrega etc. Em alguns países da Europa, como por exemplo na França, o vendedor da indústria deve passar por "negociações em cascata", que começam em uma dita "super-central de compras" de caráter nacional, para terminar em um departamento regional ou em uma unidade isolada (supermercado). Em cada uma das etapas este vendedor deve rever seus preços e promoções.

* Heterogeneidade dos mercados. Esta é uma outra característica dos mercados em questão, sendo igualmente válida nagement, 1992: BLANC, F.

Marketing industriel. Paris:

Vuibert Entreprise, 1988. 
para as relações agroindústria/agroindústria e agroindústria/distribuiçāo. Ao lado de grandes grupos agroindustriais pode-se encontrar um enorme tecido de P.M.E. (pequenas e médias empresas), que compōe a franja dos oligopólios. É óbvio que o relacionamento entre uma P.M.E. e um grande grupo agroindustrial coloca em jogo uma relaçăo de força desigual. $\mathrm{O}$ "poder" do fornecedor vis à vis do comprador se intensifica à medida que a participação dos seus produtos no faturamento deste último aumenta, seja na comercialização de um produto de referência (incontornável dentro de de-
* Colaboração entre comprador e vendedor. Como será visto, esta pode ser uma característica marcante do Marketing Agrícola. Da mesma forma, essa mesma característica está longe de ser negligenciável no âmbito do Marketing Agroindustrial. A relação de cooperação entre agroindústria/agroindústria e agroindústria / distribuiçāo pode se dar sob várias formas, como explicitado a seguir. Uma indústria fornecedora tem interesse em estreitar as relações com seus clientes importantes, a fim de moldar o seu marketing-mix o melhor possível a cada un dos clientes. Isso permitiria diminuir

\section{A formação de um complexo agroindustrial exige a participação de um conjunto de cadeias produtivas.}

terminado mercado), seja no caso de uma importância estratégica particular do produ to comercializado ou ainda quando os custos de substituição dos produtos săo elevados ${ }^{16}$. Relação análoga pode ser observada entre as grandes empresas agroindustriais e os pequenos supermercados e mercearias. No caso brasileiro, nāo se deve esquecer os atacadistas que compram das fábricas e se incubem de distribuir as mercadorias aos pequenos varejistas. Pelo volume de compras, esses atacadistas, assim como as grandes cadeias de supermercados, podem obter melhores condições das grandes empresas industriais.

* Demanda derivada. Esta característica está na essência da noção de agribusiness. Este assunto já foi discutido anteriormente e nāo cabe repassá-lo. No entanto, é importante relembrar a importância das relaçōes de compra e venda e das variáveis tecnológicas no interior das cadeias que compõem os complexos agroindustriais que definirão a estrutura de determinada cadeia. a elasticidade-preço pelos produtos da empresa e (característica primordialmente técnica) aumentar os "custos de substituiçāo". O caso das fábricas de margarina industrial, principalmente Sanbra e Gessy Lever, adotam essa estratégia para adaptar as características dos seus produtos às fábricas de biscoitos e assimilados. A colaboração entre agroindústria/ distribuiçāo pode se dar sob várias formas: embalagem "específica", promoçōes diferenciadas, publicidade conjunta etc. Não se deve esquecer que, em ambos os casos, uma relação de confiança entre parceiros comerciais pode ser um elemento importante de diferenciação, tornando-se, desta forma, uma fonte de vantagem concorrencial.

\section{Marketing Agrícola}

Os mercados relacionados ao Marketing Agrícola estão situados entre as agroindústrias e a agricultura. A primeira característica deste mercado é o elevado número de produtores face ao reduzido número de compradores. É o mercado que mais se aproxima de uma concorrência pura e per-
16. PORTER, M. Op. Cit. 
feita. Os problemas que porventura ocorrerem serão, primordialmente, o resultado de forças oligopsônicas.

O surgimento das cooperativas de produção agrícola é, justamente, dentre outras, uma das formas que os agricultores encontraram para fazer frente ao poder oligopsônico de alguns grandes compradores (no Brasil existem 5 milhões de produtores rurais para somente $50 \mathrm{mil}$ agroindústrias). As cooperativas que também desenvolvem atividades industriais servem para valorizar a produçāo dos agricultores, ausentes, dentro de alguns limites, nestes mercados, proporcionando assim o contato direto da cooperativa com a distribuição ou com o consumidor final.

Este mercado é, por natureza, composto por produtos tipicamente indiferenciáveis (commodities), embora exista uma tendência cada vez mais forte de diferenciar os produtos já a partir da produção agrí- do país. Nesse caso, os grandes frigoríficos podem proporcionar, aos seus "integra-

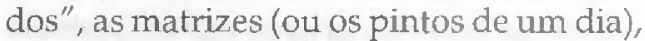
a tecnologia de manejo, a assistência veterinária, o capital, a garantia da compra da produção, para que os agricultores produzam conforme suas especificaçōes. Esse tipo de "integração", por razōes que nāo cabem ser discutidas neste trabalho, possui acusadores e defensores entre os agricultores. No entanto, alguns industriais do setor creditam a esse sistema o sucesso de suas empresas. De qualquer maneira, a existência das "redes" de agricultores capitaneadas por grandes frigoríficos é um dado que năo pode ser ignorado. Do ponto de vista prático, a empresa desejosa de atuar neste mercado terá pela frente uma grande empresa, com um departamento de compras e vendas bem montado, e não um mercado atomizado de pequenos proprietários rurais. Esse fato altera sobremanei-

\section{O Marketing Alimentar possui duas vertentes: o marketing do produto e o marketing de distribuição.}

17. ZYLBERSZTAJN, D. P\&De a coordena çāo do agribusiness. Sāo Paulo: FEAUUSP, 1993 (mimeo).

18. REIS, A.J., MORAIS, V.A., SETTE, R.S. Comercializą̧ão agric ola e Marketing Rural. LavIas: ESALFAEPE, 1991. cola ${ }^{17}$. A atitude principal do marketing desses produtos de difícil diferenciação é saber comprar e vender na hora certa. Neste sentido, as bolsas de futuro exercem papel importante para regularizar e disciplinar o mercado.

Uma possível fonte de diferenciação pode estar baseada na relação de confiança e parceria entre comprador e vendedor. Pode haver também uma distinção no nível das características dos produtos, posto que elas podem ser mais ou menos adaptadas a certos processos produtivos. Existem ainda outras fontes de diferenciação possíveis: regiăo de origem, época da cotheita, propriedades organolépticas etc.

Este mercado, em algumas ocasióes, pode caracterizar-se por uma estreita colaboraçāo entre agroindústria e produtor rural. Este é o caso, por exemplo, dos produtores integrados de suínos e aves, do sul ra a estratégia de Marketing a ser" utilizada. Além disso, a criação e a manutençāo dessas "redes de integrados" pode representar uma barreira à entrada de novas empresas desejosas de atuar no setor.

\section{Marketing Rural}

O Marketing Rural já é conhecido no Brasil desde fins do anos 70, quando foi criada a ABMR (Associação Brașileira de Marketing Rural). Em 1984 ocorreu a I Congresso da ABMR, que aprofundou e ajudou a delimitar as questōes da área. O Marketing Rural foi definido, na ocasiāo, como sendo aquele aplicado às empresas do setor agropecuário $^{18}$. Desta forma, faziam parte do universo de estudo não somente as relaçōes produtoras de insumos agropecuários/produtor rural mas também as relações de mercado estabelecidas entre as propriedades rurais e as agroindústrias e/ou 
consumidores finais (caso de produtos nãoindustrializados). Neste trabalho, definese o Marketing Rural como sendo somente aquele estabelecido entre produtores de insumos e os proprietários rurais, estando a interface entre o proprietário rural e agroindústria e/ou consumidor final compreendido no Marketing Agrícola.

Este é um mercado heterogêneo, onde coexistem produtores artesanais, produtores capitalistas (integrados aos complexos e utilizadores de insumos e tecnologia modernas) e cooperativas. Aliás, esses critérios, aliados a outros tais como tamanho da propriedade, destino da produção, tipo de cultura, nível de mecanização etc., podem servir como critérios pertinentes à segmentação desse mercado. É evidente que a estratégia pode variar muito, por exemplo, segundo o porte da empresa fornecedora, o porte do comprador, o valor e a periodicidade das compras realizadas.

De maneira geral, pode-se dizer que o consumidor de insumos agropecuários no Brasil possui as seguintes características $^{19}$ :

- produtos pouco diferenciados;

- propriedades rurais isoladas e distanciadas dos centros de informações e decisões;

- baixo nível educacional do empresariado rural;

- tradicionalismo e falta de mentalidade comercial;

- empresas geralmente carentes de técnicas de gerenciamento modernas;

- estrutura de produção atomizada;

- necessidade de empresas que comercializem serviços agregados aos produtos físicos.

Face a uma clientela com estes problemas, pode-se encontrar um grupo de fornecedores de insumos com uma estrutura concentrada e utilizador de modernas técnicas de gestão, inclusive as de Marketing. O mercado de insumos agropecuários é largamente dominado por empresas multinacionais, bem organizadas em forma de lobby, o que aumenta sobremaneira o seu poder não só frente ao proprietário rural mas também em relação aos poderes governamentais.

Uma das características do marketing de algumas dessas empresas é o contato direto e contínuo com o agricultor. Nestes casos, pelas características do produtor rural, citadas precedentemente, para se vender o produto também é preciso dar ao agricultor as informações técnicas necessárias à sua utilização. Esse tipo de trabalho serve também como forma de tornar o agricultor "fiel" ao produto da empresa. Assim, essas empresas mobilizam constantemente um número muito grande de agrônomos, com o objetivo de prestar assistência direta ao proprietário rural na utilização do produto em questão. À medida que a concorrência se acirra em alguns mercados, este "corpo-a-corpo" intensifica-se ainda mais.

Ainda, para essas empresas é imprescindível o monitoramento do comportamento do consumidor final de alimentos. Por exemplo, a recente tendência, nos países desenvolvidos, de aumento do consumo de produtos alimentares menos sujeitos à aplicação de defensivos agrícolas químicos, deu um grande impulso nas pesquisas dos defensivos e adubos ditos biológicos.

\section{CONCLUSÃO}

Pelo exposto, pode-se concluir que o Marketing, quando estudado sob a ótica de uma cadeia agroindustrial, assume características que podem variar consideravelmente segundo os vários mercados que o articulam. Nesse sentido, torna-se impossível definir instrumentos de Marketing que sejam homogêneos e aplicáveis em todos os mercados que participam da dinâmica de funcionamento do SAI. Cada um destes mercados demanda uma adaptação especial das várias ferramentas doMarketing genérico. Contudo, as metodologias clássicas de análise e recomendações mercadológicas delas decorrentes podem, sem dúvida, ser adaptadas e devidamente utilizadas. Este é um primeiro trabalho exploratório, que merece ser aprofundado com vistas à determinação dos limites de atuação de cada um dos "Marketings" enumerados, assim como de aprimoramento das adaptaçōes necessárias.
19. Idem, ibidem. 